Tohoku J. exp. Med., 1984, 143, 129-140

\title{
Primary Culture of Human Esophageal Epithelial Cells
}

\author{
Masafumi Katayama, Takashi Akaishi, Tetsuro \\ Nishihira, Morio Kasai, Mikio Kan* and Isao Yamane* \\ Second Department of Surgery, Tohoku University School \\ of Medicine and ${ }^{*}$ Cell Biology Division, Research Institute \\ for Tuberculosis and Cancer, Tohoku University, Sendai \\ 980
}

Katayama, M., Akaishi, T., Nishinira, T., Kasai, M., Kan, M. and Yamane, I. Primary Culture of Human Esophageal Epithelial Cells. Tohoku J. exp. Med., 1984, 143(2), 129-140 — Primary cultures and serial passages of nontumorous adult human esophageal epithelial cells derived from surgically resected esophagi of patients with esophageal cancer have been developed. Disaggregated cells obtained by means of tryptic digestion lasting for $90 \mathrm{~min}$ grew to confluency in medium RITC 80-7 supplemented with $10 \%$ fetal bovine serum (FBS). Such primary cultures were established from more than 20 donors, and could be passaged 3 to 5 times. Fibroblastic contamination was almost eliminated by careful sampling, and it was possible to perform the growth response or serial passages without fibroblastic overgrowth. Serum-free medium RITC 80-7 supplemented with fibronectin (FN) and bovine serum albumin (BSA) also supported the growth of esophageal epithelial cells, but was not sufficient for serial passages. Among growth promoting factors in medium RITC 80-7, the epidermal growth factor (EGF) was highly stimulatory to growth. Insulin, transferrin, FN and BSA also enhanced cell growth and/or attachment. The epithelial nature of the cultured cells was confirmed by transmission electron microscopy and indirect immunofluorescent staining with antikeratin antibody. The majority of the cultured cells were diploid. - epithelial cultures; human esophageal epithelial cells; medium RITC 80-7; cell growth factors

For the in vitro study of human esophageal epithelial cells, organ culture techniques have ordinarily been utilized (Autrup and Stoner 1982 ; Bachir et al. 1982). Human (Banks-Schlegel and Green 1981) and rabbit (Doran et al. 1980) esophageal epithelial cells were reported to have been cultured from disaggregated cells in the presence of lethally irradiated 3T3 cells for the purpose of immunofluorescent staining, grafting, or keratin analysis. Stef et al. (1981), utilizing explant culture methodology, demonstrated normal rabbit esophageal epithelial

Received for publication, September 26, 1983.

Abbreviations : BSA, bovine serum albumin ; FBS, fetal bovine serum ; FN,fibronectin; HEL, human diploid fibroblasts derived from embryo lung; MEM, Eagle's minimum essential medium. 
cell growth in a monolayer culture. Such cells were reported to have been passaged 5 times and maintained for more than 100 days.

Recently we developed a serum-free medium RITC 80-7 and succeeded in long term serial passages of human diploid fibroblasts derived from embryo lung (HEL) using this medium supplemented with fibronectin (FN) and bovine serum albumin (BSA) (Kan and Yamane 1982a). We attempted to apply this medium to human esophageal epithelial cell cultures. When medium RITC 80-7 was supplemented with $10 \%$ fetal bovine serum (FBS), excellent growth was observed in the primary culture. We report here conditions for routine methods of primary cultures and serial passages of esophageal epithelial cells. In addition, this report describes the effect of serum or some growth promoting factors and characteristics of these cells.

\section{Materials And Methods}

\section{Primary cultures}

Nontumorous human esophageal epithelia were obtained from esophageal cancer patients aged 40 to 77 years. Surgically resected esophagi were cut open longitudinally, then the epithelium was stained with Lugol's solution to distinguish carcinoma from normal epithelium (Brodmerkel 1971). Nontumorous epithelium which was sufficiently apart from the carcinoma was obtained from the esophagus. The epithelium was dissected free through the submucous plane with surgical knives. The epithelium was then cut into approximately $1 \mathrm{~cm}^{2}$ pieces. To eliminate fibroblastic contamination, the submucous tissue was carefully peeled off with fine forceps.

Each piece was minced with knives and digested for $90 \mathrm{~min}$ at $37^{\circ} \mathrm{C}$ in $5 \mathrm{ml}$ of $\mathrm{Ca}^{++}$, $\mathrm{Mg}^{++}$-free phosphate buffered saline (PBS) containing $0.025 \%(\mathrm{~W} / \mathrm{V})$ trypsin $(2 \mathrm{X}$ crystalline, Miles Co., Elkhart, IN, USA) and $0.02 \%$ (W/V) EDTA. The suspension was pipetted and centrifuged to pellet the cells, which were then resuspended in $3 \mathrm{ml}$ of RITC 80-7 supplemented with $10 \%$ FBS, $100 \mu \mathrm{g} / \mathrm{ml}$ sodium piperacillin (Toyama Chemical Co., Tokyo) $5 \mu \mathrm{g} / \mathrm{ml}$ gentamicin (Schering Copr., Kenilworth, NJ, USA) and $5 \mu \mathrm{g} / \mathrm{ml}$ amphotericin B (Sigma Chemical Co., St. Louis, MO, USA). After allowing the undigested fragments to settle, cells in the turbid supernatant were counted and plated into a $60-\mathrm{mm}$ petri dish (Lux). Ordinarily an inoculum of 1.5 to $3 \times 10^{6}$ cells per $60-\mathrm{mm}$ petri dish was needed to produce confluence in primary cultures and could be obtained from an approximately $1 \mathrm{~cm}^{2}$ piece of epithelium.

The cultures were maintained at $37^{\circ} \mathrm{C}$ in a humidified atmosphere at $5 \% \mathrm{CO}_{2}$ in air. After 4 days the medium was replaced with $3 \mathrm{ml}$ of RITC 80-7 supplemented with $10 \%$ FBS without antibiotics, and cells were fed every 4 days with fresh medium. After 6-10 days the cultures became confluent. Such confluent cultures could be subcultured.

\section{Subculture}

Medium was removed from a confluent culture dish. The cells were rinsed with PBS and incubated in $2 \mathrm{ml}$ of $0.025 \%$ trypsin and $0.02 \%$ EDTA in PBS for 30 to $80 \mathrm{~min}$ at $37^{\circ}$ C. The loosened cells were then pipetted to break up clumps. The resulting suspension was combined with two 2-ml rinses of the petri dish with PBS and centrifuged to pellet the cells. The pelleted cells were subcultured by resuspending them in RITC 80-7 supplemented with $10 \%$ FBS and inoculating the cells into $60-\mathrm{mm}$ petri dishes at a $1: 2$ dilution. Some of the cultures were cryopreserved for later use. 
Media

Modified Eagle's minimum essential medium (modified MEM) was purchased from Nissui Seiyaku Co. (Tokyo). Medium RITC 80-7, based on modified MEM, was prepared in our laboratory as previously described (Kan and Yamane 1982a). This medium was developed as a serum-free medium and was used usually with additions of FN (10 mg/liter) and BSA (5 g/liter) as previously described (Kan and Yamane 1982a), but was also used with the addition of FBS in this study. FBS was purchased from GIBCO (Grand Island, NY, USA). FN was prepared from citrated human blood plasma by gelatin sepharose affinity column chromatography (Engvall and Ruoslahti 1980). BSA (Cohn's Fr. V) was purchased from Sigma Chemical Co. (St. Louis, MO, USA).

\section{Growth response experiments}

All the inocula for growth response experiments were prepared from secondary cultures. Secondary cultures were fed every 4 days with fresh medium until the cultures became confluent, usually after 5-10 days of growth. Confluent cells were harvested in the same manner as was done in subculturing. For serum-free medium experiments, soybean trypsin inhibitor (Sigma Chemical Co., St. Louis, MO, USA, Type 1-S) was applied to stop the tryptic action. The cell pellet was resuspended in PBS and the cells were counted. The cells were then plated into 35-mm petri dishes ( $\mathrm{Lux}$ ) and incubated at $37^{\circ} \mathrm{C}$ with a gas phase of either $18 \%$ (atmospheric oxygen) or $7 \% \mathrm{O}_{2}$ and $5 \% \mathrm{CO}_{2}$. For cultures in a low oxygen environment, an $\mathrm{O}_{2}-\mathrm{CO}_{2}$ incubator (Tabai Co., Osaka) was used. The number of cells in each dish was determined by dissociating the culture with $0.0075 \%$ (W/V) pronase-E (Kaken Co., Tokyo) and $0.02 \%$ EDTA in PBS. The dispersed cells were then counted with a micro cell counter (Type CC-118, TOA Co., Kobe). The number of cells was determined on duplicate dishes.

\section{Immunofluorescence}

Rabbit antiserum specific for human keratin was obtained from Dr. Michiko Hosokawa, Department of Dermatology, Tohoku University School of Medicine (Hosokawa et al. 1981). Fluorescein isothiocyanate (FITC)-conjugated goat antirabbit IgG was obtained from Miles Research Products (Elkhart, IN, USA). Cultured cells to be stained were grown in Lab-Tek tissue culture chamber/slides (Miles Laboratories Inc., Naperville, IL, USA), rinsed briefly with PBS, and fixed at room temperature for $30 \mathrm{~min}$ in $3.7 \%$ formaldehyde in PBS. The fixed cells were rinsed with $\mathrm{PBS}$ and treated with prechilled methanol at $-20^{\circ} \mathrm{C}$ for $5 \mathrm{~min}$, after which they were rinsed again with $\mathrm{PBS}$ and incubated for $30 \mathrm{~min}$ at $37^{\circ} \mathrm{C}$ in antikeratin serum diluted 1: 80 with PBS. They were then rinsed with PBS, incubated for $30 \mathrm{~min}$ with FITC-conjugated goat antirabbit IgG diluted 1: 10 with PBS, and rinsed again with PBS. They were examined by means of a Nikon fluorescence microscope (Sun et al. 1979).

\section{Electron microscopy}

Cultures to be subjected to electron microscopy were fixed in $2.5 \%$ glutaraldehyde in $0.1 \mathrm{M}$ sodium cacodylate buffer ( $\mathrm{PH} 7.4$ ), and postfixed in $1 \%$ osmium tetroxide in $0.1 \mathrm{M}$ sodium cacodylate buffer. The fixed cells were dehydrated with a series of graded ethanol $(50-100 \%)$, and the cells were embedded in Epon 812. Ultrathin sections were made with an LKB ultramicrotome and observed with an electron microscope (JEOL, Model 100C), after double staining with uranyl acetate and lead acetate.

\section{Chromosome analysis}

Near confluent cells were treated with colcemide (GIBCO, Grand Island, NY, USA) at a final concentration of $0.1 \mu \mathrm{g} / \mathrm{ml}$ for $4 \mathrm{hr}$. Then cells were harvested and resuspended in a hypotonic solution $(0.075 \mathrm{M} \mathrm{KCl})$, and incubated for $15 \mathrm{~min}$ at $37^{\circ} \mathrm{C}$. Fixation was carried out three times in Carnoy's fixative, and cells were dropped on a chilled wet slide 
glass (50\% ethanol) and stained with Giemsa solution. The number of chromosomes of 100 to 120 metaphases were counted.

\section{RESUlts}

\section{Primary cultures}

Tryptic digestion during a considerable period gave a good yield of cells. The cell yield increased with an increase in the period of tryptic digestion and was maximal at $90 \mathrm{~min}$, and the cell yield at $120 \mathrm{~min}$ was similar to that at $90 \mathrm{~min}$ (Table 1). This result is also shown in the photograph of cultured dishes after a 5 day incubation (Fig. 1). Therefore, tryptic digestion lasting for $90 \mathrm{~min}$ was employed in the routine procedure.

Fibroblast-like cells could be almost eliminated by careful sampling. Submucous tissue which contained stromal cells were carefully peeled off with fine forceps. Cultures derived from such pure sample of epithelium contained very few fibroblast-like cells. In these cultures fibroblastic overgrowth was not recognized.

Confluent primary cultures were stratified and showed epithelial-like morpho-

TABLE 1. Yield of esophageal epithelial cells with tryptic digestion for various time intervals

\begin{tabular}{cccccc}
\hline & \multicolumn{5}{c}{ Time interval during digestion } \\
& $10 \mathrm{~min}$ & $30 \mathrm{~min}$ & $60 \mathrm{~min}$ & $90 \mathrm{~min}$ & $120 \mathrm{~min}$ \\
\hline $\begin{array}{c}\text { Number of } \\
\text { cells released }\end{array}$ & 0 & $2.1 \times 10^{4}$ & $6.9 \times 10^{4}$ & $5.1 \times 10^{5}$ & $5.0 \times 10^{5}$ \\
\hline
\end{tabular}

The esophageal epithelium was cut into 5 pieces having the same area $(3 \times 3 \mathrm{~mm})$. These pieces were each minced and digested in $2 \mathrm{ml}$ of $0.025 \%$ trypsin and $0.02 \%$ EDTA in PBS at $37^{\circ} \mathrm{C}$. Cells released from the tissues after incubation for 10, 30, 60, 90 or 120 min were collected and counted.

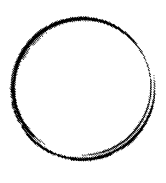

$10 \mathrm{~min}$

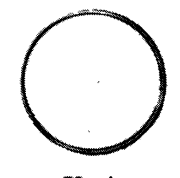

$30 \mathrm{~min}$

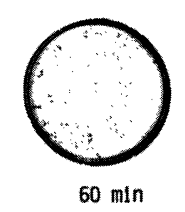

$60 \mathrm{~min}$

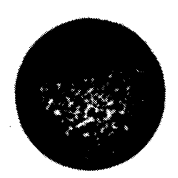

$90 \mathrm{~min}$

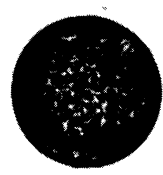

$120 \mathrm{~min}$

Fig. 1. Primary cultures of esophageal epithelial cells with tryptic digestion for various time intervals. $3 \times 3 \mathrm{~mm}$ fragments of esophageal epithelium were digested in trypsin solution for various time intervals. Cells released from tissues were resuspended in $1.5 \mathrm{ml}$ of RITC $80-7$ supplemented with $10 \%$ FBS and plated into $35-\mathrm{mm}$ petri dishes. After a 5 day incubation period, cultures were fixed and stained. 


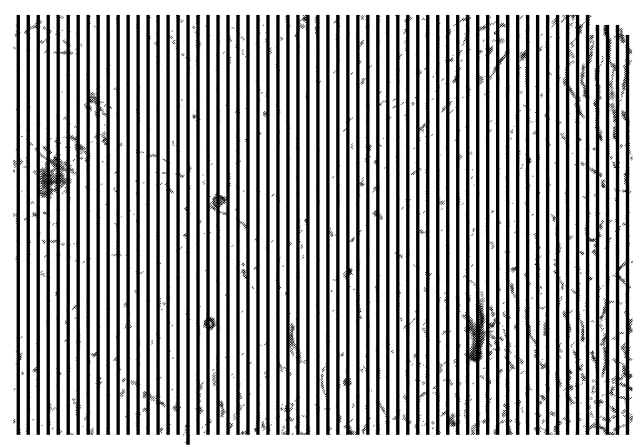

Fig. 2. Phase contrast micrographs showing the morphology of esophageal epithelial cells grown in RITC 80-7 supplemented with 10\% FBS. Confluent primary culture on day 8 was stratified and showed epithelial-like morphology $(\times 72)$.

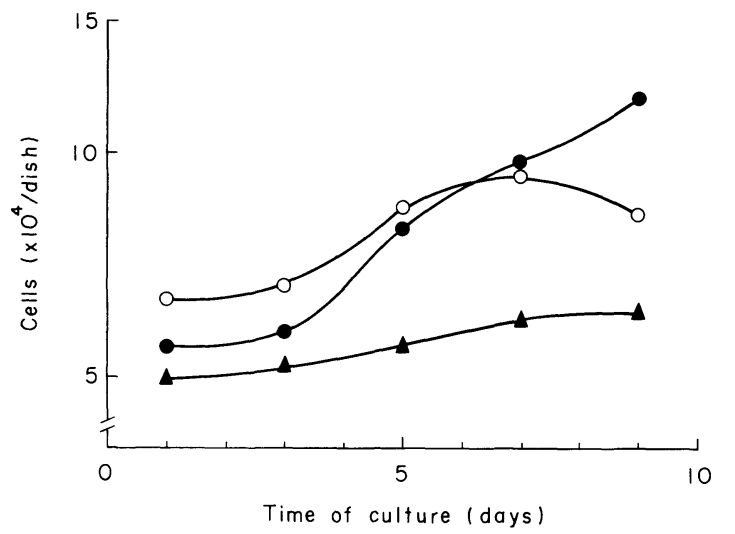

Fig. 3. Cell growth of esophageal epithelial cells in three different media. Cells $(1 \times$ $10^{5}$ ) were cultured in $1.5 \mathrm{ml}$ of RITC $80-7$ supplemented with $10 \%$ FBS $(\bullet)$, RITC 80-7 supplemented with FN and BSA (O), or modified MEM supplemented with 10\% FBS ( $\mathbf{\Delta})$. Results are means of duplicate dishes.

logy (Fig. 2). Primary cultures from more than 20 donors were routinely esta'olished.

\section{Growth kinetics}

To study the growth kinetics of esophageal epithelial cells, the cells were cultured in three different media (modified MEM with 10\% FBS, RITC 80-7 with 10\% FBS and RITC 80-7 with FN and BSA) (Fig. 3). Although cells did not grow well in modified MEM with 10\% FBS, RITC 80-7 with 10\% FBS supported cell growth; the population doubling time was approximately $120 \mathrm{hr}$. Serumfree medium RITC 80-7 with FN and BSA also supported growth, but after 7 days, growth declined and cell lysis took place. As previously reported, HEL cells cultured in this serum-free medium showed lysis in an atmospheric oxygen 
environment but not in a low $(7 \%$ ) oxygen environment (Kan and Yamane 1982b). Therefore, the growth kinetics in this serum-free medium was also surveyed in a low $(7 \%)$ oxygen environment. Growth declined and cell lysis took place after 7 days of culture in an atmospheric oxygen environment, but such phenomena was not recognized in a low (7\%) oxygen environment (Fig. 4). Therefore, subsequent studies using this serum-free medium were routinely made in a low $(7 \%)$ oxygen environment. In a low $(7 \%)$ oxygen environment, however, this serum-free medium was not sufficient for serial passages. Cultures grown in this serum-free medium ceased to grow after one passage.

\section{Effect of serum}

The effect of serum supplementation on the cell yield was ascertained. Fig. 5 shows the concentration dependent effects of serum on the cell yield. In

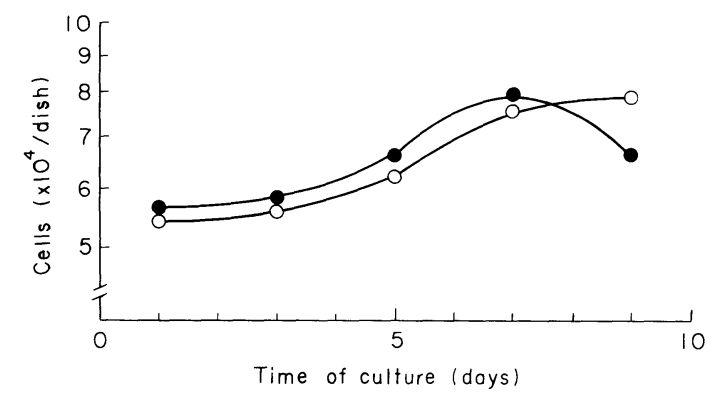

Fig. 4. Effect of different oxygen environments on growth of esophageal epithelial cells. Cells $\left(1 \times 10^{5}\right)$ were cultured in $1.5 \mathrm{ml}$ of RITC $80-7$ supplemented with FN and BSA in an atmospheric $(\bullet)$ or low $(7 \%)(\bigcirc)$ oxygen enviroment. Results are means of duplicate dishes.

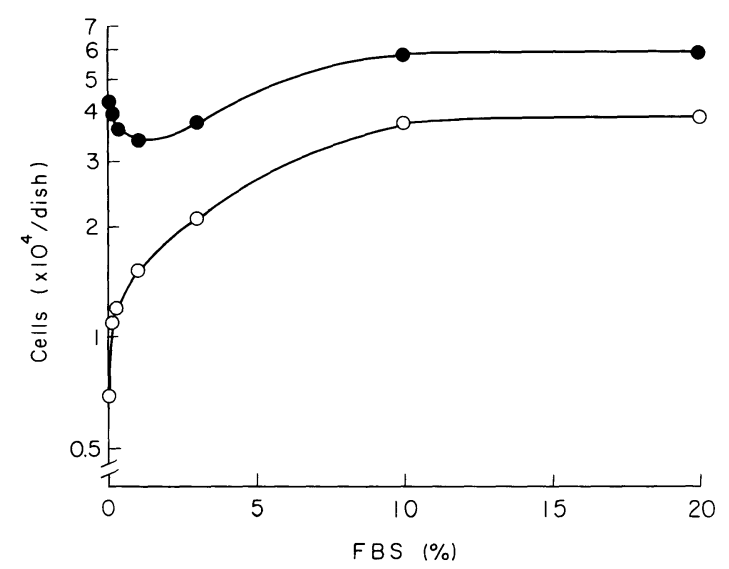

Fig. 5. Effect of serum concentration on the cell yield of esophageal epithelial cells in two different media. Medium RITC 80-7 (•) or modified MEM ( $\bigcirc)$ was supplemented with $20,10,3,1,0.3,0.1$, or $0 \%$ of FBS. Cells $\left(8 \times 10^{4}\right)$ were plated in 1 . $5 \mathrm{ml}$ of each medium and counted on day 5 . Results are means of duplicate dishes. 
modified MEM, the cell yield increased in proportion to the serum concentration. On the other hand, in medium RITC 80-7 the cell yield decreased as the serum concentration was increased to $1 \%$, but the cell yield increased at levels of more than $1 \%$. In both media, the optimum concentration for FBS was more than $10 \%$. Serum changed cellular morphology and cell-to-cell arrangements. In medium RITC 80-7 without serum, cells were tightly apposed and piled up, whereas serum supplementation promoted the spreading of cells, and the cell-tocell arrangement became more "epithelial-like" (data not shown).

Effect of $B S A, F N$, insulin, transferrin and epidermal growth factor (EGF)

Insulin, transferrin and EGF were the main growth promoting factors in medium RITC 80-7 as previously described (Kan and Yamane 1982a). In a serum-free culture, BSA and FN were ordinarily added to medium RITC 80-7 to promote the growth or cell attachment (Kan and Yamane 1982a).

The effect of these 5 substances on cell growth or attachment was ascertained. These 5 substances were deleted one at a time from RITC 80-7 supplemented with $\mathrm{BSA}$ and FN. Insulin, transferrin and EGF were also deleted together at one time. Under these conditions, cell attachment was reduced in the absence of BSA or FN (Fig. 6). Deletion of FN or EGF remarkably reduced cell growth, and a substantial reduction was also observed in the absence of BSA, insulin or transferrin (Fig. 7). BSA changed the cellular morphology and cell-to-cell arrangements in the same manner as did serum (date not shown).

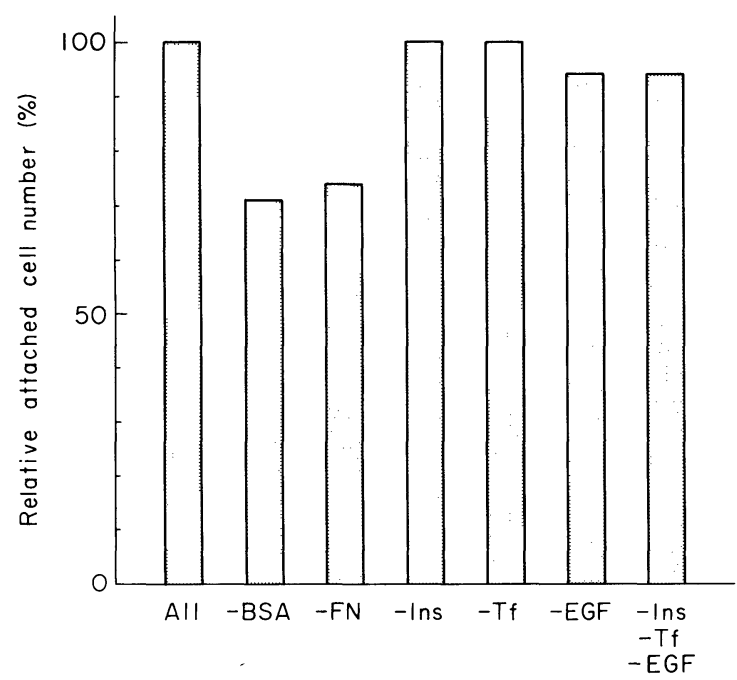

Fig. 6. Effect of removing individual factors from serum-free medium RITC 80-7 supplemented with FN and BSA on cell attachment of esophageal epithelial cells. Cells $\left(8 \times 10^{4}\right)$ were plated in $1.5 \mathrm{ml}$ of each medium. Attached cells were counted after overnight incubation under a low $(7 \%)$ oxygen environment. The number of cells is presented relative to the number of attached cells in RITC 80-7 supplemented with FN and BSA (All). Results are means of duplicate dishes. 


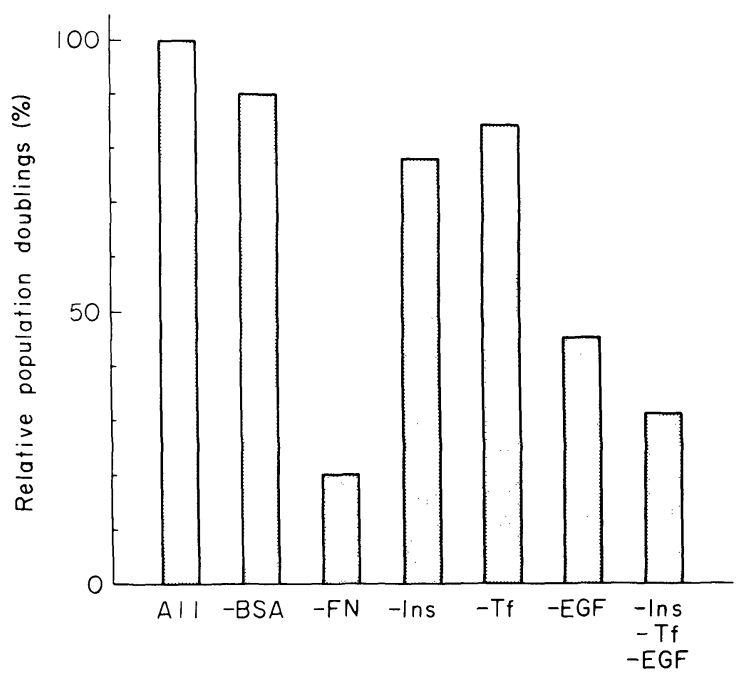

Fig. 7. Effect of removing individual factors from serum-free medium RITC 80-7 supplemented with FN and BSA on cell growth of esophageal epithelial cells. Cells $\left(8 \times 10^{4}\right)$ were plated in $1.5 \mathrm{ml}$ of each medium. Cells were counted after 1 and 7 days of growth under a low $(7 \%$ ) oxygen environment. The number of population doublings for 6 days was calculated from the number of attached cells (day 1) and harvested cells (day 7). Population doublings are presented relative to population doublings in RITC 80-7 supplemented with FN and BSA (All). Results are means of duplicate dishes.

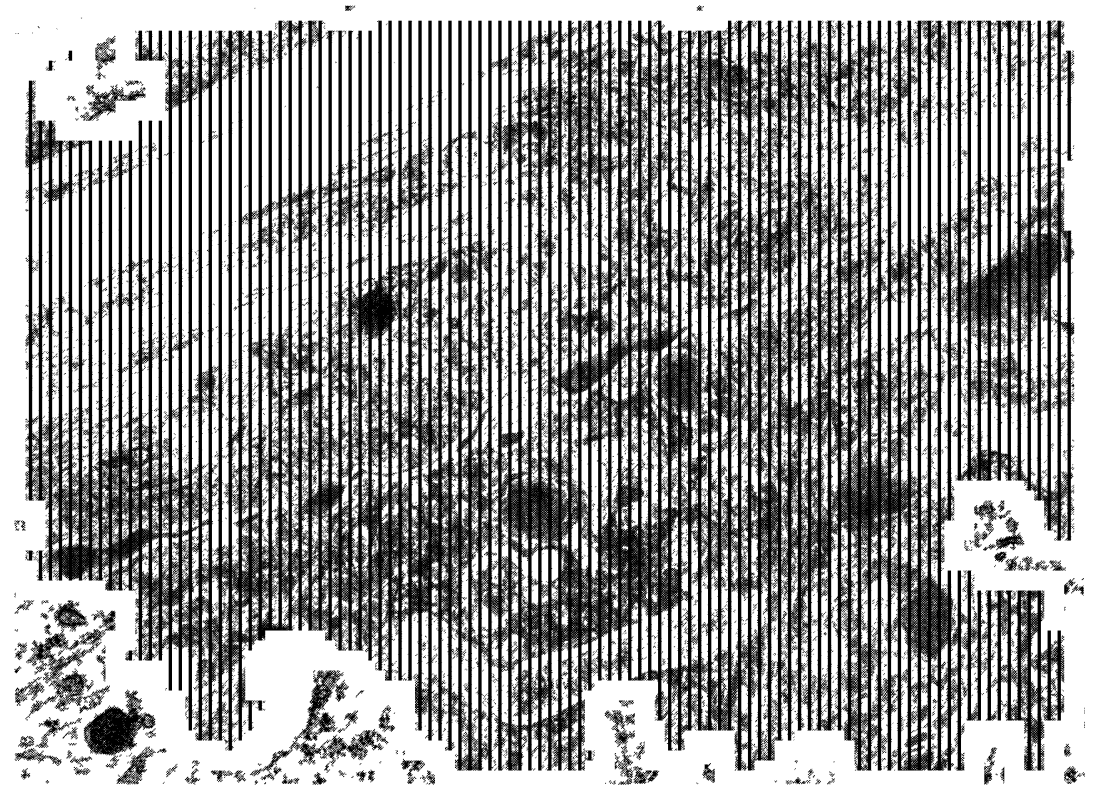

Fig. 8. Transmission electron microscopy of cultured esophageal epithelial cells in cross section. At the upper left is the free surface of cultured cells. Cultured cells are stratified and show numerous tonofilament bundles and desmosomes $(\times 25,600)$. 


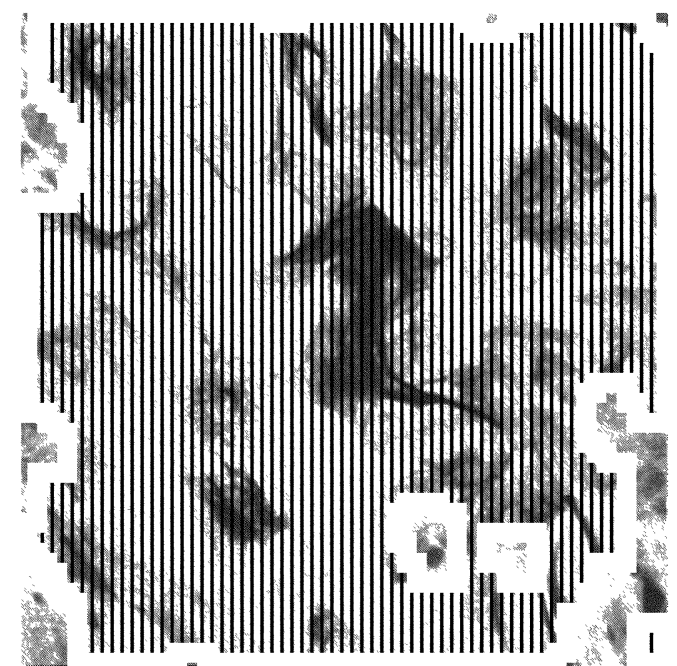

Fig. 9. Immunofluorescent staining of cultured esophageal epithelial cells with antikeratin antibody. Cells were plated in medium RITC 80-7 supplemented with $10 \%$ FBS. Staining was carried out as described in Materials and Methods. Fibrous structure of stained keratin can be seen. Note the absence of nuclear staining $(\times 360)$.

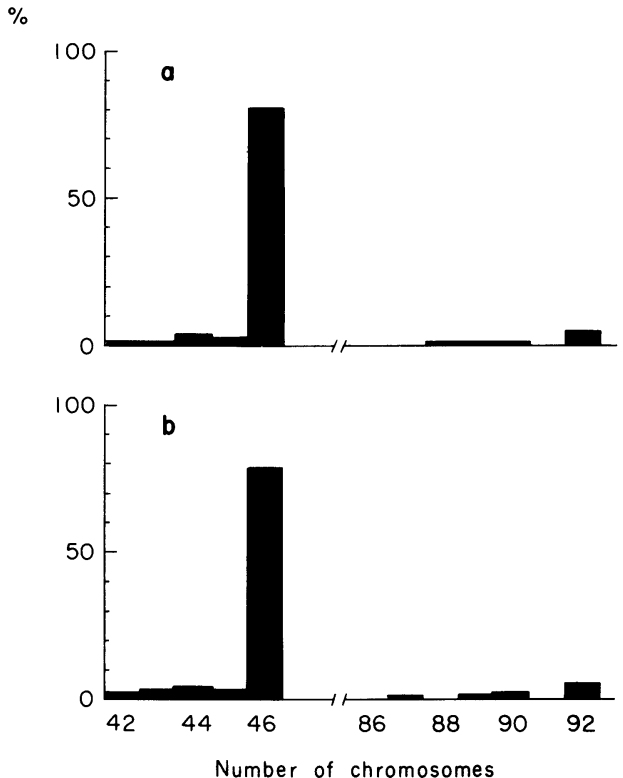

Fig. 10. Distribution histogram of chrmosomes from esophageal epithelial cells. The number of chromosomes of 100 metaphases in a subconfluent primary culture (a) and 120 metaphases in a subconfluent secondary culture (b) were counted. 


\section{Characterization}

Transmission electron microscopy of esophageal epithelial cells in secondary culture demonstrated cell stratification, numerous tonofilament bundles and desmosomes (Fig. 8). Immunofluorescent staining showed keratins to be present in the cultured esophageal epithelial cells (Fig. 9). Fibrous staining could be seen in the cytoplasm without nuclear staining.

Distributions of chromosome numbers in a primary culture and in a secondary culture are shown in Fig. 10. The modal chromosome number was 46 (approximately $80 \%$ ). Some tetraploids were also present $(8 \%$ in a primary culture, $10 \%$ in a secondary culture).

\section{Discussion}

Ham (1982) described that normal epithelial cells are difficult to grow in culture with standard media. Formerly, esophageal epithelial cells also grew only slightly in standard media such as modified MEM supplemented with $10 \%$ FBS. However, medium RITC 80-7 supplemented with 10\% FBS supported the growth of esophageal epthelial cells.

Serum was necessary for the culture of esophageal epithelial cells, especially for serial passages. In modified MEM the cell yield increased in proportion to the serum concentration. On the other hand, supplementation of medium RITC 807 with serum resulted in a somewhat complicated response. The inhibitory effect of serum at levels less than $1 \%$ suggests that there is a combination of effects of serum and supplements in medium RITC 80-7 or that other inhibitory factors exist in serum.

Serum-free medium RITC 80-7 supplemented with FN and BSA also supported the growth of esophageal epithelial cells. However, cells ceased to grow relatively earlier in serum-free medium than in serum-supplemented RITC 80-7, and serum-free medium could not support serial passages. We previously reported that HEL cells could be passaged serially in serum-free medium RITC 80-7 supplemented with FN and BSA as in serum-supplemented medium (Kan and Yamane 1982a). In contrast to HEL cells, esophageal epithelial cells are supposed to require some factors which are missing in this serum-free medium but that exist in serum for serial passages.

Ham (1982) has reported that most, if not all, types of normal cells appear to have absolute requirements for macromolecular supplementation. Tsao et al. (1982) reported that EGF, insulin and transferrin stimulated the growth of human epidermal keratinocytes, but that FN preparation was not effective. Though esophageal epithelial cells responded to EGF, insulin and transferrin in the same manner as human epidermal keratinocytes, in the absence of FN preparation a substantial reduction of cell attachment and growth was observed. Gilchrest et al. (1980) also demonstrated that an FN matrix provides a biologically relevant 
surface for attachment of human epidermal keratinocytes in vitro. BSA stimulated cell attachment and growth of esophageal epithelial cells in the presence of FN preparation.

It is very important to show that the cultured cells are indeed epithelial in nature. In addition to their morphological appearance in culture, the cultured cells were immunostained with antikeratin antibody. The results were consistent with those of another experiment in which the stratified squamous esophageal epithelium cross-reacted with the antikeratin antibody (Sun et al. 1979). Transmission electron micrscopic studies further revealed the epithelial-like characteristics of cultured cells.

We can now routinely establish primary cultures of esophageal epithelial cells, which can be serially passaged without fibroblastic overgrowth. We can also perform growth response assay not only in serum-supplemented medium but also in serum-free medium. However, at present our technique and medium are not sufficient for long term serial passages. Ham (1982) found that properly optimized medium could provide a selective advantage in the growth of epithelial cells. Therefore, we think optimization will resolve some problems and be possible with our present techniques. The culture system reported here make it potentially possible to investigate cultured esophageal epithelial cells as the control in the in vitro study of esophageal cancer. In addition, this culture system is potentially useful for a variety of investigations of esophageal epithelial cells, e.g., aging, differentiation and carcinogenesis.

\section{Acknowledgments}

We thank Dr.M. Hosokawa for supplying us with antikeratin serum for this study and M. Kato for her excellent technical assistance.

\section{References}

1) Autrup, H. \& Stoner, G.D. (1982) Metabolism of N-nitrosamines by cultured human and rat esophagus. Cancer Res., 42, 1307-1311.

2) Bachir, G.S., Collis, J.L. \& Joffe, S.N. (1982) The toxicity of bile salt conjugates on human esophageal epithelium grown in tissue culture. J. Surg. Res., 32, 547-554.

3) Banks-Schlegel, S. \& Green, H. (1981) Involucrin synthesis and tissue assembly by keratinocytes in natural and cultured human epithelia. J. Cell Biol., 90, 732-737.

4) Brodmerkel, G.J., Jr. (1971) Shiller's test: An aid in esophageoscopic diagnosis. Gastroenterology, 60, 813.

5) Doran, T.I., Vidrich, A. \& Sun, T.T. (1980) Intrinsic and extrinsic regulation of the differentiation of skin, corneal and esophageal epithelial cells. Cell, 22, 17-25.

6) Engvall, E. \& Ruoslahti, E. (1980) Binding of soluble form of fibroblast surface protein, fibronectin, to collagen. Int. J. Cancer, 20, 1-5.

7) Gilchrest, B.A., Nemore, R.E. \& Maciag, T. (1980) Growth of human keratinocytes on fibronectin-coated plates. Cell Biol. Int. Rep., 4, 1009-1016.

8) Ham, R.G. (1982) Importance of the basal nutrient medium in the design of hormonally defined media. In: Growth of Cells in Hormonally Defined Media, Book A, edited by G.H. Sato, A.B. Pardee \& D.A. Sirbasku, Vol. 9. Cold Spring Harbor 
Laboratory, New York, pp. 39-60.

9) Hosokawa, M., Masu, S. \& Seiji, M. (1981) Immunofluorescence studies on Civatte bodies and dyskeratotic cells with anti-keratin antibody. Tohoku J. exp. Med., 135, 219-229.

10) Kan, M. \& Yamane, I. (1982a) In vitro proliferation and lifespan of human diploid fibroblasts in serum-free BSA-containing medium. J. Cell Physiol., 111, 155-162.

11) Kan, M. \& Yamane, I. (1982b) Effects of sulfhydryl groups and oxygen tension on the cell proliferating activity of bovine serum albumin in culture. Cell Struct. Func., 7, 133-143.

12) Stef, J.J., Zboralske, F.F. \& Karasek, M.A. (1981) In vitro culture of rabbit esophageal epithelial cells. Gastroenterology, 81, 30-60.

13) Sun, T.T., Shih, C. \& Green, H. (1979) Keratin cytoskeletons in epithelial cells of internal organs. Proc. nat. Acad. Sci. USA, 76, 2813-2817.

14) Tsao, M.C., Walthall, B.J. \& Ham, R.G. (1982) Clonal growth of normal human epidermal keratinocytes in a defined medium. J. Cell Physiol., 110, 219-229. 